\title{
Thermal ablation of large unresectable hepatocellular carcinoma in cirrhotic patients
}

\author{
Giovan Giuseppe Di Costanzo, Raffaella Tortora, Anna Opramolla, Marco Guarracino \\ Transplantation Department, Liver Unit, A Cardarelli Hospital, Naples 80131, Italy. \\ Correspondence to: Dr. Giovan Giuseppe Di Costanzo, Transplantation Department, Liver Unit, A Cardarelli Hospital, Via A. Cardarelli 9, \\ Naples 80131, Italy. E-mail: ggdicostanzo@libero.it
}

\begin{abstract}
How to cite this article: Di Costanzo GG, Tortora R, Opramolla A, Guarracino M. Thermal ablation of large unresectable hepatocellular carcinoma in cirrhotic patients. Hepatoma Res 2018;4:53. http://dx.doi.org/10.20517/2394-5079.2018.56
\end{abstract}

Received: 11 May 2018 First Decision: 19 Jun 2018 Revised: 10 Jul 2018 Accepted: 10 Jul 2018 Published: 17 Sep 2018

Science Editors: Guang-Wen Cao Copy Editor: Huan-Liang Wu Production Editor: Zhong-Yu Guo

\begin{abstract}
Hepatocellular carcinoma (HCC) is one of the most common and lethal malignancies worldwide. Surgery is the mainstay of treatment, but less than $20 \%-30 \%$ of patients are good candidates. Actually, thermal ablation is considered the best treatment with curative intent for cirrhotic patients with unresectable $\mathrm{HCC} \leq 3 \mathrm{~cm}$. Unfortunately, radio frequency efficacy in obtaining the complete ablation of HCC nodules diminishes with increasing tumor size and local tumor progression is more frequent in larger nodules. To overcome these problems, higher-powered generators, different devices and techniques have been attempted. Furthermore, microwave ablation has been introduced with the promise of a large ablative capacity. The aim of this review is to describe the role of thermal ablation for the treatment of large unresectable HCC.
\end{abstract}

Keywords: Hepatocellular carcinoma, hypertermic ablation, radiofrequency, microwave ablation

\section{INTRODUCTION}

Hepatocellular carcinoma (HCC) is one of the most common and lethal malignancies worldwide. Surgery is the mainstay of treatment, but less than $20 \%-30 \%$ of patients are good candidates mainly due to cancer multifocality, position of nodules, liver insufficiency, and severe portal hypertension ${ }^{[1]}$. When feasible, resection ensures better local control of cancer and longer disease-free survival, but it carries a higher rate of complication as compared to local ablation ${ }^{[2,3]}$. In early 1990's, thermal ablation with radiofrequency (RFA) has been introduced for the treatment of HCC. This technique has become increasingly popular and a large amount of studies have been published confirming its efficacy. Actually, thermal ablation is considered the best treatment with curative intent for cirrhotic patients with unresectable $\mathrm{HCC} \leq 3 \mathrm{~cm}^{[4-8]}$.

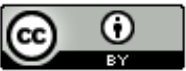

(C) The Author(s) 2018. Open Access This article is licensed under a Creative Commons Attribution 4.0 International License (https://creativecommons.org/licenses/by/4.0/), which permits unrestricted use, sharing, adaptation, distribution and reproduction in any medium or format, for any purpose, even commercially, as long as you give appropriate credit to the original author(s) and the source, provide a link to the Creative Commons license, and indicate if changes were made.

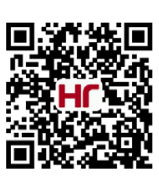


In nodules up to $2 \mathrm{~cm}$ in size, RFA allows the complete ablation in more than $90 \%$ of cases and may obtain results comparable to surgery ${ }^{[9-11]}$. Randomized studies have shown higher efficacy of RFA as compared to chemical ablation with ethanol achieving the complete necrosis of HCC nodules $\leq 3 \mathrm{~cm}$ with fewer sessions and reducing the rate of local cancer progression ${ }^{[12-14]}$. Unfortunately, RFA efficacy in obtaining the complete ablation of HCC nodules diminishes with increasing tumor size and local tumor progression is more frequent in larger nodules ${ }^{[15,16]}$. The lower efficacy of ablation in nodules larger than $3 \mathrm{~cm}$ is also due to a more aggressive biological behaviour of large cancers, as high levels of biomarkers, poor histological grade or capsule invasion ${ }^{[17]}$. Viable tumor cells after partial ablation may develop "resistance" to heat and may exhibit a more aggressive growth ${ }^{[18]}$. Furthermore, the position of nodules and the amount of blood flow inside and at periphery of nodules may affect the ablative effect of RFA (heat-sink effect) ${ }^{[1,20]}$. To overcome these problems, higher-powered generators, different devices and techniques have been attempted. Furthermore, microwave ablation (MWA) has been introduced with the promise of a large ablative capacity. The treatment of large HCC lesions represents a great challenge for clinicians because the late diagnosis of such cancer is not rare despite the use of surveillance. A careful multidisciplinary evaluation of liver function, cancer characteristics, and patient status is needed to establish the best treatment in the single case.

The aim of this review is to describe the role of thermal ablation ablation for the treatment of large unresectable HCC.

\section{RADIO FREQUENCY ABLATION}

In a seminal study by Livraghi and Coll, 114 patients with 126 nodules larger than $3.0 \mathrm{~cm}$ were treated with single or triple cluster of cool-tip monopolar electrodes. Complete ablation was achieved in $61 \%$ of nodules in the size range $3.1-5.0 \mathrm{~cm}$, and only in $24 \%$ of nodules $5.1-9.5 \mathrm{~cm}^{[21]}$. To improve these results, a protocol derived from a mathematic model was applied to calculate preoperatively the site and the number of needle insertions ${ }^{[22]}$. The model was based on the analysis of how many overlapping ablation spheres were needed to cover the HCC nodule. To ablate nodules sized 3.6-7.0 cm, 1-13 electrode placements were performed. The success rate in 121 nodules was $87 \%$. A limitation of the application of such protocol was the difficulty in determining the accurate placement of needles in larger lesions. Using an open approach and single or cluster cool-tip needles a complete ablation rate of $91 \%$ may be achieved in nodules of $3.5-8.0 \mathrm{~cm}^{[23]}$. "Surgical RFA" as compared to percutaneous RFA showed similar efficacy in small nodules, but was associated to better survival rates in patients with larger $\mathrm{HCC}^{[24]}$. However, with this approach the rate of complications and post-RFA liver impairment was higher as compared to patients treated percutaneously. The highest rate of complete ablation using cool-tip needles has been reported in a large Asian cohort. The authors achieved a complete necrosis in $98.9 \%$ of 360 treatments for HCC $3.1-5.0 \mathrm{~cm}$, and in $97.7 \%$ of 44 treatments for tumors $>5.0 \mathrm{~cm}^{[25]}$. These results have never been reproduced in a Western study. In order to increase the ablation area bipolar and multipolar electrodes have been attempted. The use of bipolar devices may allow a better distribution of temperature inside the tissue ${ }^{[26]}$. In a small prospective study including 26 patients with 27 tumors $5.0-8.5 \mathrm{~cm}$, three separate bipolar internally cooled electrodes achieved the complete ablation in 22 among 27 nodules (81\%), including three tumors that showed segmental portal vein invasion ${ }^{[27]}$. However, multipolar electrodes resulted more effective than monopolar devices in obtaining the complete necrosis of nodules up to $4.5 \mathrm{~cm}$, but in larger tumors the efficacy was comparable ${ }^{[28]}$. Another way to increase the ablation area is the use of expandable electrodes and interstitial saline infusion that may create lesions significantly larger than not cooled needles ${ }^{[29]}$. However, in small HCC internally cooled electrodes compared to expandable electrodes had similar effectiveness ${ }^{[30]}$. A strategy to increase the efficacy of RFA in larger nodules is the insertion of multiple needles inside the tumor that may be alternatively activated using a swichting algorytm ${ }^{[31,32]}$. However, with the devices actually available, RFA ablative capacity in nodules $>5 \mathrm{~cm}$ is scarce. To overcome the limited efficacy of RFA in larger nodules, combination treatments of RFA plus percutaneous ethanol injection or plus transarterial chemoembolization (TACE) have been attempted. In Eastern studies, in combining these treatments, a higher rate of cancer ablation and a better overall and recurrence-free survival than RFA alone have been reported ${ }^{[33-41]}$. 
Another possibility may be the combined treatment with sorafenib and RFA or triple combination also with TACE, with the aim of increasing the necrosis and reducing the rate of recurrence ${ }^{[42-44]}$. Regarding complications of RFA ablation, in a large survey 6 deaths (0.3\%) were observed. Five of these patients had large HCC complicating cirrhosis, in 3 patients the cancer nodules were located in risky areas and two had Child-Pugh $\mathrm{B}$ cirrhosis ${ }^{[45]}$. Therefore, caution should be observed in such cases. Major and minor complications occurred in $2 \%$ and $5 \%$, respectively. Similar rates have been observed in more recent studies ${ }^{[46,47]}$. A pre-RFA value of bilirubin $>2.5 \mathrm{mg} / \mathrm{dL}$ may predict liver decompensation after treatment ${ }^{[48]}$.

\section{MICROWAVE ABLATION}

Due to the advancement of microwave technology and the development of cooled electrodes, percutaneous microwave ablation (MWA) is actually considered a safe and effective alternative to RFA for thermal ablation of $\mathrm{HCC}^{[49,50]}$. As compared to RFA, MWA has theoretical advantages including the shorter procedural time, very rapid increase in tissue temperature, and it is less affected by tissue impedance and the heat-sink effect $^{[51]}$. Both in ex vivo and in vivo porcine liver model, MWA produced larger coagulation zones than bipolar $\mathrm{RFA}^{[52]}$.

Two metanalyses comparing the two techniques have been published ${ }^{[3,54]}$. Chinnaratha et al ${ }^{[54]}$ analyzing three studies including 450 patients with HCC nodules $>5.0 \mathrm{~cm}$ or more than 3 nodules found a benefit for MWA as compared to RFA with a pooled OR of $1.88^{[55-57]}$. Furthermore, MWA treatment was associated with a lower rate of local tumor progression in large HCC as compared to RFA. The evaluation of studies including larger HCC and the metanalysis of Facciorusso et al confirmed that MWA was significantly more effective than RFA in inducing the complete necrosis of tumours ${ }^{[5,59]}$. Also other authors confirmed MWA is safe and effective in the treatment of large $\operatorname{HCC}^{[60,61]}$ and subcapsular lesion ${ }^{[62]}$.

A recent randomised controlled trial did not show superiority of MWA over RFA in terms of efficacy, major complications and local tumour progression at 2 years of follow-up in patients with hepatocellular carcinoma lesions of $4 \mathrm{~cm}$ or smaller ${ }^{[63]}$, confirming a previous study published in $2002^{[64]}$. Chong et al. ${ }^{[65]}$ suggested to apply ALBI score for the selection of patients in order to identify the cases with worse liver function in whom to prefer MWA to surgery.

More than overlapping insertions, the placement of multiple antennas may obtain larger ablation areas, mainly when simultaneous activation is used ${ }^{[6]]}$. This is an advantage as compared to RFA that do not allow the simultaneous activation of multiple electrodes. Another approach is the insertion of electrode under laparoscopic guidance. This technique resulted effective in small nodules, but it might be useful for the treatment of large nodules with an exophytic growth ${ }^{[67]}$. A study in 14 centers on 736 patients treated with MWA using the AMICA system found 22 (2.9\%) major complications, 54 (7.3\%) minor complication, and no deaths ${ }^{[47]}$.

\section{LASER ABLATION}

Laser ablation (LA) is the less popular technique for performing thermal ablation and there is only one casecontrol study designed to evaluate the efficacy of this treatment in large HCC. This study compared LA with the multifiber technique and TACE for the treatment of solitary large HCC with a diameter of $4.0-7.5 \mathrm{~cm}^{[68]}$. LA approach resulted more effective than TACE in inducing complete tumour necrosis. Overall, 26 (63.4\%) patients from the LA group and 8 (19.5\%) from the TACE group showed a complete response to treatment $(P<0.001)$. In univariate analyses, baseline predictors of complete response were Child-Pugh class A and treatment modality with LA. Furthermore, the rate of local cancer progression was observed in $19.5 \%$ of LA successfully treated patients and in $75 \%$ of TACE treated $(P<0.001)$. In nodules with a median diameter of $5.2 \mathrm{~cm}(3.1-9.6 \mathrm{~cm})$, combined treatment with LA performed before TACE obtained the complete ablation in $90 \%$ of 45 tumours in 30 patients $^{[69]}$. In our Unit, a study evaluating the use of sorafenib as neoadjuvant 
therapy in patients with large HCC who receive LA is ongoing. A multicenter Italian study evaluated the rate and type of complications after LA with the multifiber technique. Among 520 patients and 1004 sessions, 4 deaths (0.8\%), 15 major complications (1.5\%), and 62 minor complications (6.2\%) were observed. All deceased patients had intermediate or large tumours and 2 of these were in Child-Pugh C class ${ }^{[70]}$.

\section{CONCLUSION}

Thermal ablation is a very popular technique for the treatment of unresectable HCC in patients with cirrhosis. In small HCC sized $<3.0 \mathrm{~cm}$, RFA may achieve good results that in some cases are comparable to that of surgical resection. Compared to surgery, local ablation features, mini-invasive approaches, with less impact on liver function less morbidity and hospital stay and less costs. The applicability of thermal ablation in nodules $>3 \mathrm{~cm}$ which constitutes the objective of this review, is still a matter of debate. During the last 25 years, technical advances have increased the efficacy of such technique, expanding the range of its application. However, the level of evidence is poor due to the scarcity of appropriated designed randomized studies. A main problem in inducing the complete necrosis of large HCC nodules is the lack of very experienced operators. In fact it is evident that a single needle insertion is insufficient in inducing the complete necrosis of large tumors. The increase in the potency emitted by a single source may be insufficient to ablate the periphery of large nodules and may be risky causing unwanted complications. In this setting, overlapping electrode placements and multiple needle insertions are the better way to increase the treatment effectiveness. The correct placement of electrodes inside the nodules is crucial for obtaining the therapeutic success. The simultaneous activation of inserted needles seems more effective than alternate activation in inducing larger and confluent coagulation areas. Therefore, theoretically MWA and LA might be favored as compared to RFA in the treatment of large tumors. A strategy frequently used in clinical practice is the use of combined treatments, mainly percutaneous ablation and TACE. The sequential use of such treatments seems to achieve a better local tumor control, but randomized studies are awaited to define its applicability.

\section{DECLARATIONS}

\section{Authors' contributions}

Concept and design of study, drafting the article, final approval of the version to be published: Di Costanzo GG

Acquisition of data or analysis and interpretation of data; drafting the article, final approval of the version to be published: Tortora $\mathrm{R}$

Acquisition of data or analysis and interpretation of data; revising it critically for important intellectual content; final approval of the version to be published: Opramolla A

Concept and design of study; revising it critically for important intellectual content; final approval of the version to be published: Guarracino M

\section{Availability of data and materials}

Not applicable.

\section{Financial support and sponsorship}

None.

\section{Conflicts of interest}

All authors declare that there are no conflicts of interest.

\section{Ethical approval and consent to participate}

Not applicable.

Consent for publication 
Not applicable.

\section{Copyright}

(c) The Author(s) 2018.

\section{REFERENCES}

1 Bismuth H, Majno PE, Adam R. Liver transplantation for hepatocellular carcinoma. Semin Liver Dis 1999;19:311-22.

2 Feng K, Yan J, Li X, Xia F, Ma K, Wang S, Bie P, Dong J. A randomized controlled trial of radiofrequency ablation and surgical resection in the treatment of small hepatocellular carcinoma. J Hepatol 2012;57:794-802.

3 Pompili M, Saviano A, de Matthaeis N, Cucchetti A, Ardito F, Federico B, Brunello F, Pinna AD, Giorgio A, Giulini SM, De Sio I, Torzilli G, Fornari F, Capussotti L, Guglielmi A, Piscaglia F, Aldrighetti L, Caturelli E, Calise F, Nuzzo G, Rapaccini GL, Giuliante F. Long-term effectiveness of resection and radiofrequency ablation for single hepatocellular carcinoma $\leq 3 \mathrm{~cm}$. Results of a multicenter Italian survey. $\mathrm{J}$ Hepatol 2013;59:89-97.

4 Rossi S, Di Stasi M, Buscarini E, Cavanna L, Quaretti P, Squassante E, Garbagnati F, Buscarini L. Percutaneous radiofrequency interstitial thermal ablation in the treatment of small hepatocellular carcinoma. Cancer J Sci Am 1995;1:73-81.

5 Seki T, Wakabayashi M, Nakagawa T, Itho T, Shiro T, Kunieda K, Sato M, Uchiyama S, Inoue K. Ultrasonically guided percutaneous microwave coagulation therapy for small hepatocellular carcinoma. Cancer 1994;74:817-25.

6 Lencioni R, Cioni D, Crocetti L, Franchini C, Pina CD, Lera J, Bartolozzi C. Early stage hepatocellular carcinoma in patients with cirrhosis: long-term results of percutaneous image-guided radiofrequency ablation. Radiology 2005;234:961-7.

7 Lee DH, Lee JM, Lee JY, Kim SH, Yoon JH, Kim YJ, Han JK, Choi BI. Radiofrequency ablation of hepatocellular carcinoma as first-line treatment: long-term results and prognostic factors in 162 patients with cirrhosis. Radiology 2014;270:900-9.

8 Choi D, Lim HK, Rhim H, Kim YS, Lee WJ, Paik SW, Koh KC, Lee JH, Choi MS, Yoo BC. Percutaneous radiofrequency ablation for early-stage hepatocellular carcinoma as a first-line treatment: long-term results and prognostic factors in a large single-institution series. Eur Radiol 2007; 17:684-92.

9 Livraghi T, Meloni F, Di Stasi M, Rolle E, Solbiati L, Tinelli C, Rossi S. Sustained complete response and complications rate after radiofrequency ablation of very early hepatocellular carcinoma in cirrhosis. Is resection still the treatment of choice? Hepatology 2008;47:82-9.

10 Cho YK, Kim JK, Kim WT, Chung JW. Hepatic resection vs. radiofrequency ablation for very early stage hepatocellular carcinoma: a Markov model analysis. Hepatology 2010;51:1284-90.

11 Cucchetti A, Piscaglia F, Cescon M, Colecchia A, Ercolani G, Bolondi L, Pinna AD. Cost-effectiveness of hepatic resection vs. percutaneous radiofrequency ablation for early hepatocellular carcinoma. J Hepatol 2013;59:300-7.

12 Germani G, Pleguezuelo M, Gurusamy K, Meyer T, Isgro G, Burroughs AK. Clinical outcomes of radiofrequency ablation, percutaneous alcohol and acetic acid injection for hepatocelullar carcinoma: a meta-analysis. J Hepatol 2010;52:380-8.

13 Orlando A, Leandro G, Olivo M, Andriulli A, Cottone M. Radiofrequency thermal ablation vs. percutaneous ethanol injection for small hepatocellular carcinoma in cirrhosis: meta-analysis of randomized controlled trials. Am J Gastroenterol 2009; 104:514-24.

14 Cho YK, Kim JK, Kim MY, Rhim H, Han JK. Systematic review of randomized trials for hepatocellular carcinoma treated with percutaneous ablation therapies. Hepatology 2009;49:453-59.

15 Mulier S, Ni Y, Jamart J, Ruers T, Marchal G, Michel L. Local recurrence after hepatic radiofrequency coagulation: multivariate metaanalysis and review of contributing factors. Ann Surg 2005;242:158-71.

16 N'Kontchou G, Mahamoudi A, Aout M, Ganne-Carrié N, Grando V, Coderc E, Vicaut E, Trinchet JC, Sellier N, Beaugrand M, Seror O. Radiofrequency ablation of hepatocellular carcinoma: Long-term results and prognostic factors in 235 Western patients with cirrhosis. Hepatology 2009;50:1475-83.

17 Lu XY, Xi T, Lau WY, Dong H, Xian ZH, Yu H, Zhu Z, Shen F, Wu MC, Cong WM. Pathobiological features of small hepatocellular carcinoma: correlation between tumor size and biological behavior. J Cancer Res Clin Oncol 2011;137:567-75.

18 Thompson SM, Callstrom MR, Jondal DE, Butters KA, Knudsen BE, Anderson JL, Lien KR, Sutor SL, Lee JS, Thorgeirsson SS, Grande JP, Roberts LR, Woodrum DA. Heat stress-induced PI3K/mTORC2-dependent AKT signaling is a central mediator of hepatocellular carcinoma survival to thermal ablation induced heat stress. PLoS One 2016;11:e0162634

19 Lu DSK, Raman SS, Limanond P, Aziz D, Economou J, Busuttil R, Sayre J. Influence of large peritumoral vessels on outcome of radiofrequency ablation of liver tumors. J Vasc Interv Radiology 2003;10:1267-74.

20 Lu DS, Yu NC, Raman SS, Limanond P, Lassman C, Murray K, Tong MJ, Amado RG, Busuttil RW. Radiofrequency ablation of hepatocellular carcinoma: treatment success as defined by histologic examination of the explanted liver. Radiology 2005;234:954-60.

21 Livraghi T, Goldberg SN, Lazzaroni S, Meloni F, Ierace T, Solbiati L, Gazelle GS. Hepatocellular carcinoma: radiofrequency ablation of medium and large lesions. Radiology 2000;214:761-8.

22 Chen MH, Yang W, Yan K, Zou MW, Solbiati L, Liu JB, Dai Y. Large liver tumors: protocol for radiofrequency ablation and its clinical application in 110 patients-Mathematic model, overlapping mode, and electrode placement process. Radiology 2004;232:260-71.

23 Poon RTP, Ng KKC, Lam C-M, Ai V, Yuen J, Fan ST. Effectiveness of radiofrequency ablation for hepatocellular carcinomas larger than 3 cm in diameter. Arch Surg 2004;139:281-7.

24 Khan MR, Poon RT, Ng KK, Chan AC, Yuen J, Tung H, Tsang J, Fan ST. Comparison of percutaneous and surgical approaches for radiofrequency ablation of small and medium hepatocellular carcinoma. Arch Surg 2007;142:1136-43.

25 Shiina S, Tateishi R, Arano T, Uchino K, Enooku K, Nakagawa H, Asaoka Y, Sato T, Masuzaki R, Kondo Y, Goto T, Yoshida H, Omata M, 
Koike K. Radiofrequency ablation for hepatocellular carcinoma: 10-year outcome and prognostic factors. Am J Gastroent 2012;107:569-77.

26 Haemmerich D, Tungjitkusolmun S, Staelin ST, Lee FT, Mahvi DM, Webster JG. Finite-element analysis of hepatic multiple probe radiofrequency ablation. IEEE Trans Biomed Eng 2002;49:836-42.

27 Seror O, N'Kontchou G, Ibraheem M, Ajavon Y, Barrucand C, Ganne N, Coderc E, Trinchet JC, Beaugrand M, Sellier N. Large (>or=5.0$\mathrm{cm})$ HCCs: multipolar RF ablation with three internally cooled bipolar electrodes-initial experience in 26 patients. Radiology 2008;248:28896.

28 Cartier V, Boursier J, Lebigot J, Oberti F, Fouchard-Hubert I, Aubé C. Radiofrequency ablation of hepatocellular carcinoma: Mono or multipolar? J Gastroenterol Hepatol 2016;31:654-60.

29 Miao Y, Ni Y, Yu J, Zhang H, Baert A, Marchal G. An ex vivo study on radiofrequency tissue ablation: increased lesion size by using an “expandable-wet” electrode. Eur Radiol 2001;11:1841-47.

30 Shibata T, Shibata T, Maetani Y, Isoda H, Hiraoka, M. Radiofrequency ablation for small hepatocellular carcinoma: prospective comparison of internally cooled electrode and expandable electrode. Radiology 2006;238:346-53.

31 Brace CL, Sampson LA, Hinshaw JL, Sandhu N, Lee FT Jr. Radiofrequency ablation: simultaneous application of multiple electrodes via switching creates larger, more confluent ablations than sequential application in a large animal model. J Vasc Interv Radiol 2009;20:118-24.

32 Haemmerich D, Lee FT Jr. Multiple applicator approaches for radiofrequency and microwave ablation. Int J Hyperthermia 2005;21:93-106.

33 Zhang YJ, Liang HH, Chen MS, Guo RP, Li JQ, Zheng Y, Zhang YQ, Lau WY. Hepatocellular carcinoma treated with radiofrequency ablation with or without ethanol injection: a prospective randomized trial. Radiology 2007;244:599-607.

34 Cheng BQ, Jia CQ, Liu CT, Fan W, Wang QL, Zhang ZL, Yi CH. Chemoembolization combined with radiofrequency ablation for patients with hepatocellular carcinoma larger than $3 \mathrm{~cm}$ : a randomized controlled trial. JAMA 2008;299:1669-77.

35 Qi X, Zhao Y, Li H, Guo X, Han G. Management of hepatocellular carcinoma: an overview of major findings from meta-analyses. Oncotarget 2016;7:34703-51.

36 Yang P, Liang M, Zhang Y, Shen B. Clinical application of a combination therapy of lentinan, multi-electrode RFA and TACE in HCC. Advances in Therapy 2008;25:787-94.

37 Ni JY, Liu SS, Xu LF, Sun HL, Chen YT. Meta-analysis of radiofrequency ablation in combination with transarterial chemoembolization for hepatocellular carcinoma. World J Gastroenterol 2013;19:3872-82.

38 Fukuda H, Numata K, Moriya S, Shimoyama Y, Ishii T, Nozaki A, Kondo M, Morimoto M, Maeda S, Sakamaki K, Morita S, Tanaka K. Hepatocellular carcinoma: concomitant sorafenib promotes necrosis after radiofrequency ablation — propensity score matching analysis. Radiology 2014;272:598-604.

39 Peng ZW, Zhang YJ, Liang HH, Lin XJ, Guo RP, Chen MS. Recurrent hepatocellular carcinoma treated with sequential transcatheter arterial chemoembolization and RF ablation versus RF ablation alone: a prospective randomized trial. Radiology 2012;262:689-700.

40 Shibata T, Isoda H, Hirokawa Y, Arizono S, Shimada K, Togashi K. Small hepatocellular carcinoma: is radiofrequency ablation combined with transcatheter arterial chemoembolization more effective than radiofrequency ablation alone for treatment? Radiology 2009;252:905-13.

41 Wang X, Hu Y, Ren M, Lu X, Lu G, He S. Efficacy and safety of radiofrequency ablation combined with transcatheter arterial chemoembolization for hepatocellular carcinomas compared with radiofrequency ablation alone: a time-to-event meta-analysis. Korean J Radiol 2016;17:93-102.

42 Feng X, Xu R, Du X, Dou K, Qin X, Xu J, Jia W, Wang Z, Zhao H, Yang S, Guo C, Liu T, Ma K. Combination therapy with sorafenib and radiofrequency ablation for BCLC stage 0-B1 hepatocellular carcinoma: a multicenter retrospective cohort study. Am J Gastroenterol 2014;109:1891-9.

43 Li Y, Zheng YB, Zhao W, Liu B, Hu BS, He X, Huang JW, Lu LG. Sorafenib in combination with transarterial chemoembolization and radiofrequency ablation in the treatment for unresectable hepatocellular carcinoma. Med Oncol 2013;30:730.

44 Zhu K, Huang J, Lai L, Huang W, Cai M, Zhou J, Guo Y, Chen J. Medium or large hepatocellular carcinoma: sorafenib combined with transarterial chemoembolization and radiofrequency ablation. Radiology 2018;288:300-7.

45 Livraghi T, Solbiati L, Meloni MF, Gazelle GS, Halpern EF, Goldberg SN. Treatment of focal liver tumors with percutaneous radiofrequency ablation: complications encountered in a multicenter study. Radiology 2003;226:441-51.

46 Ding J, Jing X, Liu J, Wang Y, Wang F, Du Z. Complications of thermal ablation of hepatic tumours: comparison of radiofrequency and microwave ablative techniques. Clin Radiol 2013;66:608-15.

47 Lee MW, Raman SS, Asvadi NH, Siripongsakun S, Hicks RM, Chen J, Worakitsitisatorn A, McWilliams J, Tong MJ, Finn RS, Agopian VG, Busuttil RW, Lu DSK. Radiofrequency ablation of hepatocellular carcinoma as bridge therapy to liver transplantation: a 10-year intentionto-treat analysis. Hepatology 2017;65:1979-90.

48 Giorgio A, Merola MG, Montesarchio L, Merola F, Gatti P, Coppola C, Giorgio V, Calisti G. Percutaneous radiofrequency ablation of hepatocellular carcinoma in cirrhosis: analysis of complications in a single centre over 20 years. Br J Radiol 2017;90:20160804.

49 Livraghi T, Meloni F, Solbiati L, Zanus G, Collaborative Italian Group using AMICA system. Complications of microwave ablation for liver tumors: Results of a multicenter study. Cardiovasc Intervent Radiol 2012;35:868-74.

50 Lencioni R, Crocetti L. Local-regional treatment of hepatocellular carcinoma. Radiology 2012;262:43-58.

51 Wright AS, Sampson LA, Warner TF, Mahvi DM, Lee Jr FT. Radiofrequency versus microwave ablation in a hepatic porcine model. Radiology 2005;236:132-9.

52 Li X, Zhang L, Fan W, Zhao M, Wang L, Tang T, Jiang H, Zhang J, Liu Y. Comparison of microwave ablation and multipolar radiofrequency ablation, both using a pair of internally cooled interstitial applicators: results in ex vivo porcine livers. Int J Hyperthermia 2011;27:240-8.

53 Facciorusso A, Di Maso M, Muscatiello N. Microwave ablation versus radiofrequency ablation for the treatment of hepatocellular carcinoma: A systematic review and meta-analysis. Int J Hyperthermia 2016;32:339-44.

54 Chinnaratha MA, Chuang MYA, Fraser RJ, Woodman RJ, Wigg AJ. Percutaneous thermal ablation for primary hepatocellular carcinoma: a systematic review and meta-analysis. J Gastroenterol Hepatol 2016;31:294-301.

55 Lu MD, Xu HX, Xie XY, Yin XY, Chen JW, Kuang M, Xu ZF, Liu GJ, Zheng YL. Percutaneous microwave and radiofrequency ablation for 
hepatocellular carcinoma: a retrospective comparative study. J. Gastroenterol 2005;40:1054-60.

56 Xu HX, Xie XY, Lu MD, Chen JW, Yin XY, Xu ZF, Liu GJ. Ultrasound-guided percutaneous thermal ablation of hepatocellular carcinoma using microwave and radiofrequency ablation. Clin Radiol 2004;59:53-61.

57 Yin XY, Xie XY, Lu MD, Xu HX, Xu ZF, Kuang M, Liu GJ, Liang JY, Lau WY. Percutaneous thermal ablation of medium and large hepatocellular carcinoma: long-term outcome and prognostic factors. Cancer 2009;115:1914-23.

58 Abdelaziz AO, Nabeel MM, Elbaz TM, Shousha HI, Hassan EM, Mahmoud SH, Rashed NA, Ibrahim MM, Abdelmaksoud AH. Microwave ablation versus transarterial chemoembolization in large hepatocellular carcinoma: prospective analysis. Scand J Gastroenterol 2015;50:47984.

59 Vogl TJ, Farshid P, Naguib NN, Zangos S, Bodelle B, Paul J, Mbalisike EC, Beeres M, Nour-Eldin NE. Ablation therapy of hepatocellular carcinoma: a comparative study between radiofrequency and microwave ablation. Abdom Imaging 2015;40:1829-37.

60 Medhat E, Abdel Aziz A, Nabeel M, Elbaz T, Zakaria Z, Shousha H, Amer A, Fouad Fathalah W, Maher R, Musa S.Value of microwave ablation in treatment of large lesions of hepatocellular carcinoma. J Dig Dis 2015;16:456-63.

61 Xu Y, Shen Q, Liu P, Xu Z, Wu P, Lu Z, Chen Y, Huang B, Qian G. Microwave ablation for the treatment of hepatocellular carcinoma that met up-to-seven criteria: feasibility, local efficacy and long-term outcomes. Eur Radiol 2017;27:3877-87.

62 Liu F, Yu X, Cheng Z, Han Z, Sun Y, Liang P, Zhou F. Comparison of ultrasonography-guided percutaneous microwave ablation for subcapsular and nonsubcapsular hepatocellular carcinoma. Eur J Radiol 2017;91:93-8.

63 Vietti Violi N, Duran R, Guiu B, Cercueil JP, Aubé C, Digklia A, Pache I, Deltenre P, Knebel JF, Denys A. Efficacy of microwave ablation versus radiofrequency ablation for the treatment of hepatocellular carcinoma in patients with chronic liver disease: a randomized controlled phase 2 trial. Lancet Gastroenterol Hepatol 2018;3:317-25.

64 Shibata T, Iimuro Y, Yamamoto Y, Maetani Y, Ametani F, Itoh K, Konishi J. Small hepatocellular carcinoma: comparison of radio-frequency ablation and percutaneous microwave coagulation therapy. Radiology 2002;223:331-7.

65 Chong CCN, Lee KF, Chu CM, Chan AWH, Wong J, Chan SL, Lok HT, Fung AKY, Fong AKW, Cheung YS, Yu SCH, Johnson P, Lai PBS. Microwave ablation provides better survival than liver resection for hepatocellular carcinoma in patients with borderline liver function: application of ALBI score to patient selection. HPB (Oxford) 2018;20:546-54.

66 Harari CM, Magagna M, Bedoya M, Lee FT Jr, Lubner MG, Hinshaw JL, Ziemlewicz T, Brace CL. Microwave ablation: comparison of simultaneous and sequential activation of multiple antennas in liver model systems. Radiology 2015;278:95-103.

67 Cillo U, Noaro G, Vitale A, Neri D, D’Amico F, Gringeri E, Farinati F, Vincenzi V, Vigo M, Zanus G; HePaTIC Study Group. Laparoscopic microwave ablation in patients with hepatocellular carcinoma: a prospective cohort study. HPB 2014;16:979-86.

68 Morisco F, Camera S, Guarino M, Tortora R, Cossiga V, Vitiello A, Cordone G, Caporaso N, Di Costanzo GG and Italian Liver Cancer (ITA.LI.CA) group. Laser ablation is superior to TACE in large-sized hepatocellular carcinoma: a pilot case-control study. Oncotarget 2018;9:17483-90.

69 Pacella CM, Bizzarri G, Cecconi P, Caspani B, Magnolfi F, Bianchini A, Anelli V, Pacella S, Rossi Z. Hepatocellular carcinoma: long-term results of combined treatment with laser thermal ablation and transcatheter arterial chemoembolization. Radiology 2001;219:669-78.

70 Arienti V, Pretolani S, Pacella CM, Magnolfi F, Caspani B, Francica G, Megna AS, Regine R, Sponza M, Antico E, Di Lascio FM. Complications of laser ablation for hepatocellular carcinoma: a multicenter study. Radiology 2008;246:947-55. 